Drug Delivery and Translational Research

https://doi.org/10.1007/s13346-017-0467-3

\title{
Challenge in particle delivery to cells in a microfluidic device
}

\author{
Hajar Moghadas ${ }^{1,}$ Mohammad Said Saidii ${ }^{* 1,}$ Navid Kashaninejad ${ }^{1}$, Nam-Trung Nguyen ${ }^{2}$ \\ 1 School of Mechanical Engineering, Sharif University of Technology, Tehran, Iran \\ 2 Queensland Micro and Nanotechnology Centre, Griffith University, Brisbane, QLD 4111, Australia \\ moghadas@mech.sharif.edu (H.M.), navid.knejad@gmail.com (N.K.); nam-trung.nguyen@griffith.edu.au(NT.N); \\ * Correspondences: mssaidi@sharif.edu (M.S.S.); Tel.: +982166165558 \\ \# Controlled Release Society 2017
}

Published Online: 21 December 2017

\begin{abstract}
Micro and nanotechnology can potentially revolutionize drug delivery systems. Novel microfluidic systems have been employed for the cell culture applications and drug delivery by micro and nanocarriers. Cells in the microchannels are under static and dynamic flow perfusion of culture media that provides nutrition and removes waste from the cells. This exerts hydrostatic and hydrodynamic forces on the cells. These forces can considerably affect the functions of the living cells. In this paper, we simulated the flow of air, culture medium, and the particle transport and deposition in the microchannels under different angles of connection inlet. It was found that the shear stress induced by the medium culture flow is not so high to damage the cells and it is roughly uniform in the cell culture section (CCS). However, the local shear stresses in the other parts of the microchip differ by changing the angles of connection inlet. The results showed that the particle deposition was a function of the particle size, the properties of the fluid and the flow rate. At lower air flow rate, both small and large particles deposited in the entrance region and none of them reached the CCS. Once the air flow rate increased, the drag of the flow could overcome the diffusion of the small particles and deliver them to the CCS so that more than $88 \%$ of the $100 \mathrm{~nm}$ and $98 \%$ of the $200 \mathrm{~nm}$ particles deposited in the CCS. However, larger particles with average diameters in micrometers could not reach the CCS by the airflow even at high flow rate. In contract our findings indicated that both small and large particle could be delivered to the CCS by liquid flow. Our experimental data confirm that micro-particles (with diameters of 5 and 20 microns) suspended in a liquid can reach the CCS at a well-adjusted flow rate. Consequently, a liquid carrier is suggested to transport large particles through microchannels. As a powerful tool, these numerical simulations provide a nearly complete understanding of the flow field and particle
\end{abstract}


patterns in microchips which can significantly lower the trial and error in the experiment tests and accordingly save researchers considerable cost and time for drug delivery to the cell in the microchip by micro/nanocarriers.

Keywords: Lung-on-a-chip, Numerical simulation, Particle deposition, drug delivery

\section{Introduction}

Microfluidic systems have been significantly extended the in vitro investigation of healthy and cancer cell growth, diagnosis, treatment, drug delivery and the particle toxicity effect in the various organs of the human body [1-4]. These microdevices can mimic the small terminal lung airways on the real-time and dimension scale. A number of papers investigated the injury of the lung cells during the reopening process of the blocked airways due to the lung infection both experimentally and numerically using a bubble moving in the microchannels [5]. The impact of the pulmonary surfactant which is a liquid mixture of lipids and proteins that fill the alveolar space and cover the cells was examined in a microchip and shown that it lowers the surface tension on the cell at the air/liquid interface [6]. The rupture of the alveolar sac and cell death in the mechanical ventilation were modeled in a microfluidic device in which the cells were exposed to the fluid stress induced by cyclic propagation of air-liquid interface and experienced solid mechanical stresses by stretching the wall of the microchip [7]. The reaction of lung cells to the bacteria, inflammatory cytokines and silica nanoparticles [8], as well as the effect of the alveolar wall motion on the liquid secretion in pulmonary edema, a common disease caused by excess fluid in the lungs, was also modeled using microfluidic devices [9]. Many researchers were interested in investigating the responses of the pulmonary cells exposed to drug or pollution particles [10, 11]. The inhaled nanoparticles can follow the airflow and reach the alveolar sacs and cause cells to decompose or enflame $[12,13]$. Particle deposition in the airway dramatically depends on the size of the particle and the air flow rate [13-17]. To deliver particles to a given location in previous works, the particles had been first suspended in a liquid, and then the suspension was introduced into the cells $[18,19]$. Considering the in vivo vondition, however, lung epithelial cells are exposed to the aerosol during breathing. Thus, it is desirable to mimic a condition similar to that in vivo one by introducing the particle suspended in the air through microchannels [16, 17]. 
Cells in the microfluidic network are under static and dynamic perfusion of culture media or other liquid reagents. The flow field in microchannels exerts hydrostatic and hydrodynamic forces on the cells. As a living organism, cells sense and respond to the external forces exerted on them $[20,21]$. For example, the shear stress induced by continuous flow causes mechanical and morphological changes such as activating signaling pathways of cell proliferation [22], differentiation [23, 24], adhesion [25] and migration [26]. Comprehensive understanding of the forces exerted on cells in cell culture devices is a crucial factor to optimize the design performance. Computational fluid dynamic techniques is a powerful tool not only to capture the detail of the mechanical event such as flow field, force, pressure and particle deposition [27, 28] but also to predict the physiological aspect including nutrition, waste, and gasses concentration fields in the microchannels [29-34].

Commonly uncomplicated geometries have been used for the microchannel in lung-onchip microdevices $[1,2]$. All of the microchannels have a simple horizontal duct in which cells can be cultured while they are connected to inlet and outlet microchannels with different connection angles. The previous works that were concerned with the lung cell culture on the microchannel investigated the effect of the mechanical force such as liquid/water interface movement. However, the impact of different connection angles (between the inlet and the cell culture microchannel) in the flow field and the forces that exert on the cells have not reported yet. As the flow field is a function of the geometry of the channel, the hydrodynamic forces on the cells may differ in microchannels with different inlet connection angles. Moreover, all the previous works investigated the impact of the drug or toxic particles on cellsexperimentally.

To the best of our knowledge, particle simulation has not been reported for lung-on-chip microchips. Further, to transport particles effectively, a comprehensive understanding of the particle behavior, local and overall deposition in microdevices is needed. These topics are the main focus of the present work. In this paper, we will first investigate the effect of various inlet connection angles on the flow field. Next, we will evaluate particle transport and deposition in microchannels. The particle transport will be simulated for both air and liquid carriers, and the effect of particle size and the flow rate in the local and overall particle deposition will be studied. To our best knowledge, this is the first time that the particles transport and deposition in the 
microchnnals of the lung-on-chip microdevices are studied numerically. Finally, by using a liquid carrier to transport micro particles to cell culture section, we will experimentally verify our numerical simulation.

The results of the present paper can provide detailed information regarding the forces and stresses that are exerted by the flow on cells. This can help researchers to control the hydrodynamic forces in the microchannel to keep the cells safe in shorter time and lower cost compared to the time-consuming and expensive cell culture experiments. Moreover, the results of particle patterns in the microchips are especially useful in developing the drug delivery to cells using nano/macro carriers.

\section{Materials and Methods}

\subsection{Numerical simulation}

Figure 1 represents a schematic of the microchannels which are commonly used in the pulmonary cell cultures microfluidic platforms, e.g., in Refs.[9, 35]. Two vertical cylinders represent the input and output for the flow. The fluid passes through the inlet and reaches the cell culture section (CCS) that is the horizontal part of the microchannel. CCSs are identical in all the configurations, but the cylinders of the inlet and outlet are joined with different angles with respect to the CCS. Ch0, Ch45 and Ch90 are the samples in which CCS is connected to the inlet channel with zero, $45^{\circ}$ and $90^{\circ}$ angles, respectively. We were interested in the distribution of the shear stress on various parts of the microchannel and the impact of the angle of the inlet connection on particle deposition. Also, to estimate the possibility of generation of radial flow over the cells, a cavity was embedded at the bottom of the microchannel as the CCS, and the inside flow field was simulated. The height of the microchannel is $100 \mu \mathrm{m}$ and the cavity has a dimension of $100 \times 1000 \times 1000 \mu \mathrm{m}$. 


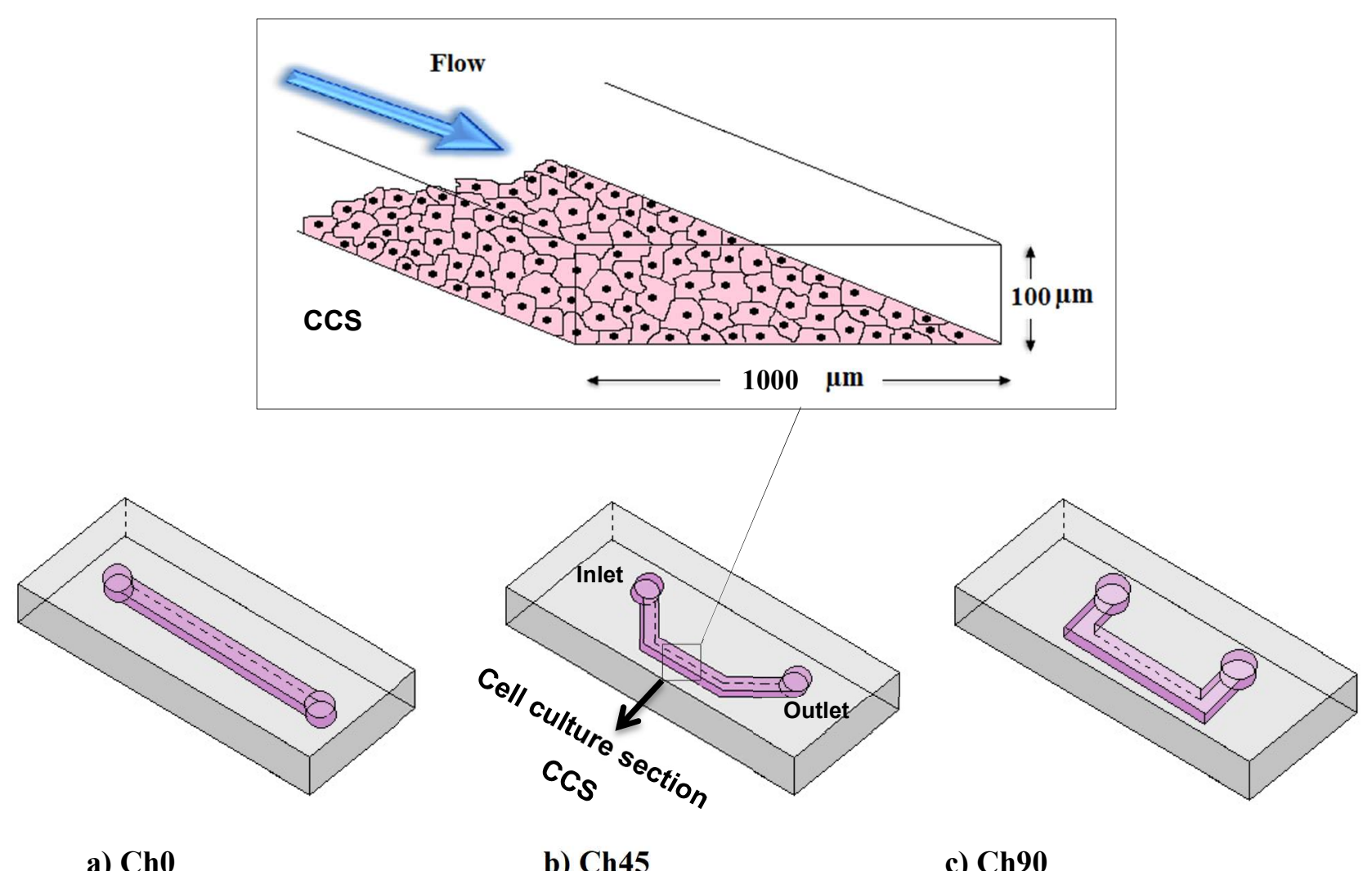
a) $\mathrm{ChO}$
b) $\mathrm{Ch} 45$
c) $\mathrm{Ch} 90$

Figure 1: An example of a typical microchannel used for the pulmonary cell cultures. a) Ch0, b) $\mathrm{Ch} 45$ and c) $\mathrm{Ch90}$ are the samples in which CCS is connected to the inlet channel with zero, $45^{\circ}$ and $90^{\circ}$ angles, respectively.

\subsubsection{Governing equations}

In general, flow in the microchannel is laminar because of the small dimensions, low velocity and low Reynolds number [36]. Therefore, the flow governing equations are continuity and momentum equations as expressed in Eq. 1 and Eq. 2, respectively.

$$
\begin{aligned}
& \nabla \cdot \vec{u}=0 \\
& \vec{u} \cdot \nabla \vec{u}=-\frac{1}{\rho} \Delta P+v \nabla^{2} \vec{u}
\end{aligned}
$$

where $\vec{u}$ is velocity vector, $\mathrm{P}$ is pressure, and $v$ and $\rho$ are density and kinematic viscosity, respectively. Eq. 1 and Eq. 2 were solved for air and medium flow in different microchannels. Physical properties of the fluid were considered at the culture temperature of $37^{\circ} \mathrm{C}$. Dulbecco's 
Modified Eagle's medium (DMEM) used in this study is a Newtonian, homogeneous and noncompressible fluid [37]. The flow conditions should provide nutrients to the cells and also produce shear stress within the range of $0.2-20 \mathrm{dyn} / \mathrm{cm}^{2}$ since high stress can damage the cells [38].

Dimensional analyses demonstrate that the significant forces exerted on the particles are drag force, Brownian force and gravity [39]. The particle transports were modeled by Lagrangian approach:

$$
\frac{d u_{p}}{d t}=F_{D}+F_{b}+g\left(1-\frac{\rho}{\rho_{p}}\right)
$$

where $u_{p}$ is the particle velocity, $F_{D}$ is the drag force, $F_{b}$ is the Brownian force, $g$ is the gravity acceleration, and $\rho_{p}$ is the particle density. Drag force, $F_{D}$, is calculated as:

$$
F_{D}=3 \pi \mu u_{r e l} d_{p}
$$

where $\mu$ is the fluid viscosity, $u_{r e l}=u_{f l u i d}-u_{p}$, and $d_{p}$ is the particle diameter, for more information, interested readers can refer to Hinds [40]. Brownian force, $F_{b}$, is calculated as:

$$
F_{b}=g_{o} \sqrt{\frac{\pi S_{o}}{\Delta t}}
$$

Here $g_{o}$ is a random number with a Gaussian distribution, $\Delta t$ is the time step and $S_{o}$ is the spectral intensity computed as:

$$
S_{o}=\frac{2 k T}{\pi m \tau}
$$

where $k$ is the Boltzmann constant, $\mathrm{T}$ is the fluid temperature, $m$ is particle mass, and $\tau$ is particle relaxation time. Detailed procedure to estimate spectral intensity is provided by Zhang and Ahmadi [41]. 
We assume that the impact of particles on the flow is negligible. Thus, the airflow field was simulated first. Then, particles trajectories were calculated. 3D computational domains with about 500,000 hexahedral elements for each sample were created, Figure 2. Finer grids study show that the results of flow field were independent of the grid number for about 950,000 cells and higher computational grids. No-slip boundary condition was imposed on the channel walls. Appling the finite volume formulation, a set of algebraic equations integrated over each control volume of the discretized computational domain. The equations were then solved by the SIMPLE algorithm. The particles were injected uniformly at the inlet. Optimum particle dispersion is a uniform release which had been shown in our previous work for the particle transport in a complex model of the human nasal airways [13]. Particle deposition efficiency was defined as the ratio of the trapped particles in the microchannel to the number of the initial particles injected from the inlet. To investigate the independence of the particle deposition efficiency from the tracked particles quantity, various amounts of particles were traced. It was revealed that the deposition efficiency was independent of the amount of the injected particles for the particle number higher than 2000. The time step of the particle trajectory was typically one order of magnitude smaller than its relaxation time. We assume that if the distance between the particle center and the wall was less than or equal to the particle radius, the particle can be trapped on the wall, and the particle rebounding is negligible. More details regarding the validity of this assumption can be found in our previous publication [13]. 


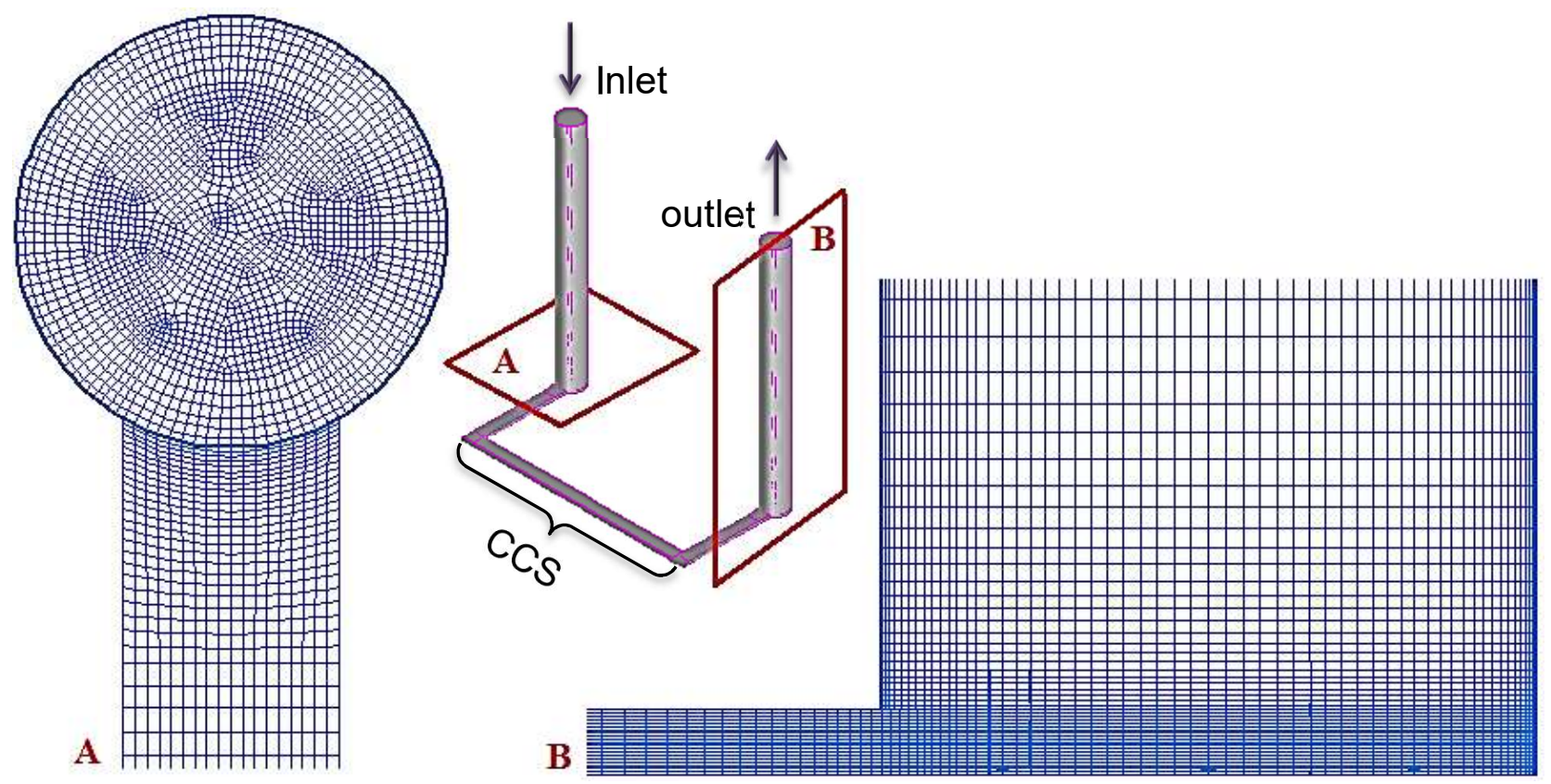

Figure 2: Grid generation in two optional planes A and B. 3D computational domains with approximately 500,000 hexahedral elements for each sample were created. The grid was created finer near the walls to capture more accurately the flow fluid and particle tracking.

\subsection{Experiment}

\subsubsection{Materials}

The microchip was made of polydimethylsiloxane (PDMS) (SYLGARD® 184 SILICONE ELASTOMER KIT) that was purchased from Sigma-Aldrich (USA). Human lung cancer cell line (A549) was obtained from the cell culture laboratory of Sharif University of Technology. Dulbecco's Modified Eagle's medium (DMEM) was provided from Sigma-Aldrich.

\subsubsection{Fabrication of microchannels}

First, the master mold of the microchannel was created on a sheet of polymethylmethacrylate (PMMA) using a computer numeric control machine. As shown in Figure 3 , the width and the height of the microchannel at the cell culture section of the device were 1000 $\mu \mathrm{m}$ and $100 \mu \mathrm{m}$, respectively. Then, PDMS pre-polymer was mixed with its curing agent in a 
weight ratio of 10:1 and poured on the PMMA master mold. The mixture was subsequently degassed for $20 \mathrm{~min}$ in a vacuum chamber and baked for 2 hours at $75^{\circ} \mathrm{C}$ in a vacuum oven. After curing, the PDMS channel was peeled off and bonded to another flat PDMS slab. To facilitate the bonding, the PDMS slabs were treated with oxygen plasma for 15 seconds.

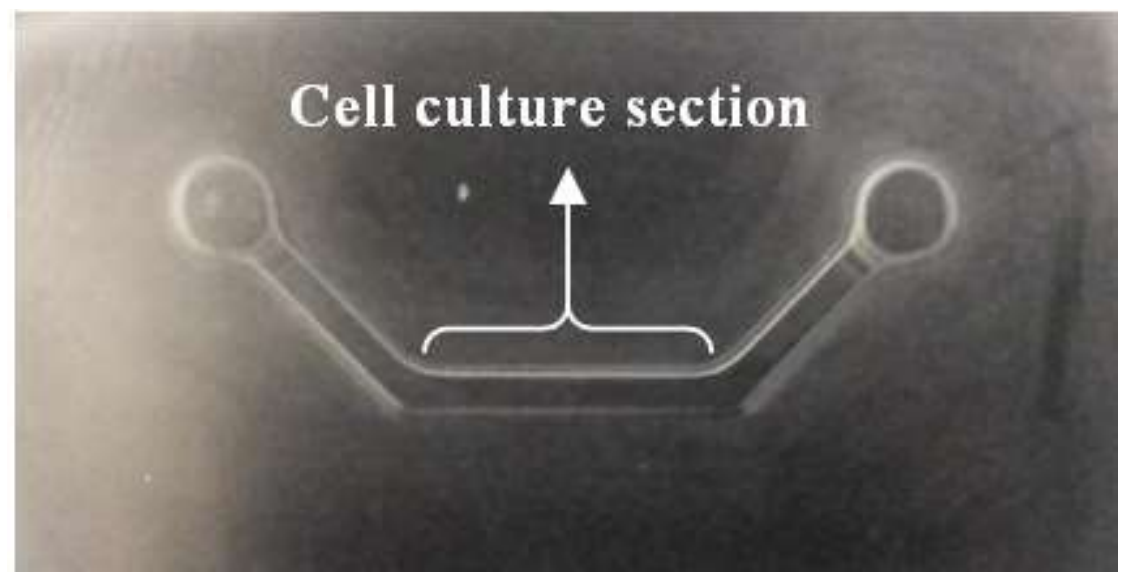

Figure 3: The master mold of the microchannel created on PMMA. The width and height of the channel were fixed at $1000 \mu \mathrm{m}$ and $100 \mu \mathrm{m}$, respectively.

\section{Results and discussion}

\subsection{Numerical simulation}

\subsubsection{Airflow}

Considering the in vivo conditions, lung epithelial cells are in contact with inhaled air. To mimic this condition for the cultivated cells in the microchannels, the airflow was simulated with two different values of inlet velocity (i.e., 0.612 and $0.1 \mathrm{~mm} / \mathrm{s}$ ) which corresponded to the airflow in alveolar duct and alveolar sac, as reported by Herman [42]. Figure 4 shows the contours of the shear stress on CCS in microchannels with $0^{\circ}, 45^{\circ}$ and $90^{\circ}$ connection angle for microchannel Ch0, Ch45 and Ch90 respectively. The distribution of the shear stress on CCS, where the cells are located, is almost uniform in all the cases except in a small reign where the CCS connected to the inlet microchannel for Ch45 and Ch90 that can be ignoredFigure 4. Therefore, all the cells in microchannels with different connecting angles sense almost the same amunt of shear stress. Consequently, shear stress gradient does not affect the culture condition. It implies that different 
angles of the inlet connection with respect to the CCS do not affect the shear forces on the cells, and the cells are under the same mechanical conditions. In addition, the average values of shear stress on the CCS are about 0.018 and $0.111 \mathrm{dyn} / \mathrm{cm}^{2}$ for the velocity inlet of 0.1 and $0.612 \mathrm{~mm} / \mathrm{s}$ respectively which are smaller than the maximum allowable value, the range of $0.2-20 \mathrm{dyn} / \mathrm{cm}^{2}$ [43].

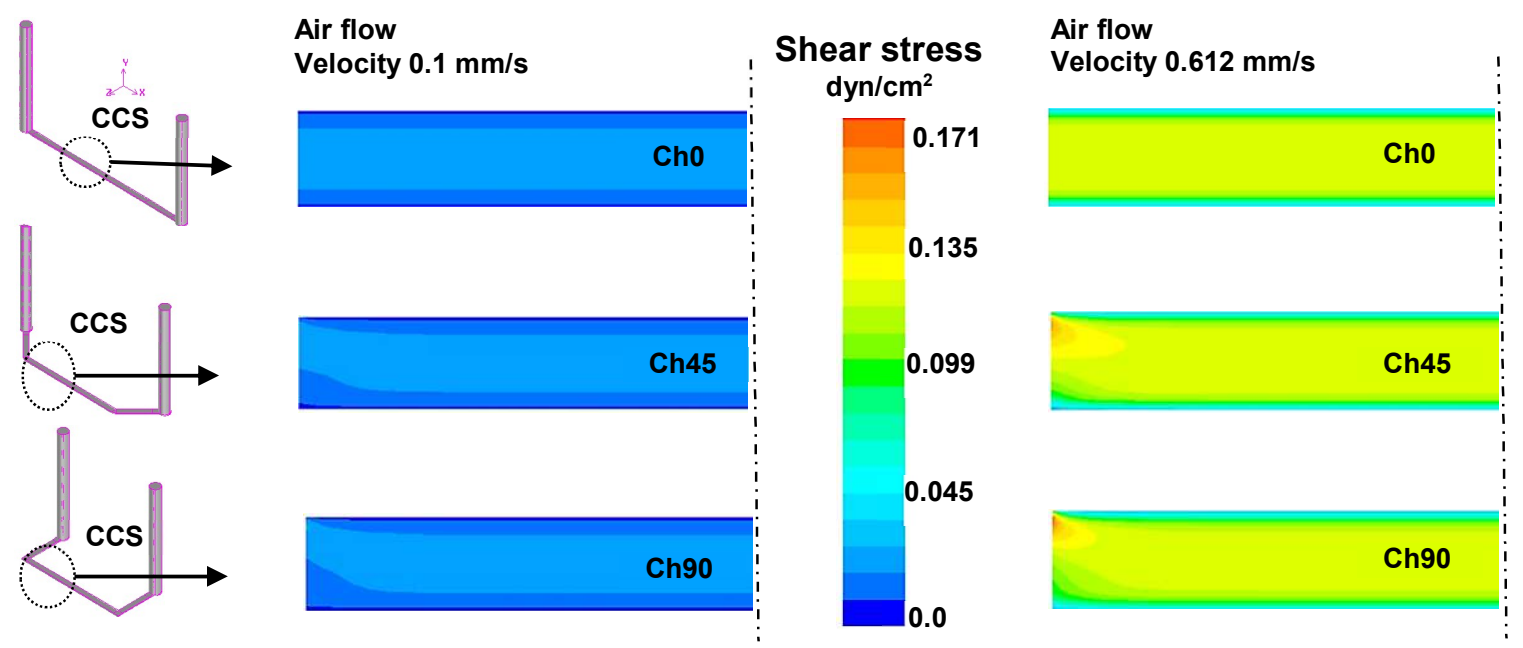

Figure 4 : Distribution of shear stress on the cells in the microchannels with different connection angles. The results were simulated under two different values of air velocity at the inlet (i.e., 0.1 and $0.612 \mathrm{~mm} / \mathrm{s}$ ).

Although the shear stress distribution is uniform and similar in the CCS of all different channels at a given flow rate, according to the data in Table 1, Ch90 has the highest values of the maximum local stress which are approximately $10 \%$ higher than those in the other channels for both velocity inlets. It may affect the cell during injection which will be discussed in detail in the next section (Medium flow). Comparing the values of shear stress for different values of inlet velocity in Table 1 it is evident that increasing the inlet velocity from 0.1 to $0.612 \mathrm{~mm} / \mathrm{s}$ (almost increasing six times) can increase the shear stress values about six times in each microchannel. That is because the flow in the microchannel is laminar, and there is a linear relationship between the flow rate and the shear stress in the internal laminar flow. 
Table 1: Maximum stress in the channels for the velocity inlet of 0.1 and $0.612 \mathrm{~mm} / \mathrm{s}$

\begin{tabular}{ccc}
\hline & \multicolumn{2}{c}{ Maximum shear stress $\left(\mathrm{dyn} / \mathrm{cm}^{2}\right)$} \\
\hline Sample & $0.1(\mathrm{~mm} / \mathrm{s})$ & $0.612(\mathrm{~mm} / \mathrm{s})$ \\
\hline Ch0 & 0.0278 & 0.170 \\
Ch45 & 0.0278 & 0.170 \\
Ch90 & 0.0303 & 0.186 \\
\hline
\end{tabular}

\subsubsection{Medium flow}

Culture medium feeds cells, discharges waste, and delivers drug and reagents to cells. According to Horsfield's model [44], blood flow rate of the pulmonary capillary is approximately $0.56 \mu \mathrm{l} / \mathrm{hr}$. However, the literature usually reported a flow rate in the range of $20-30 \mu \mathrm{l} / \mathrm{hr}$ for culture medium in the microchips [45]. Here, both orders of the reported flow rates, i.e., of 0.56 and $20 \mu \mathrm{l} / \mathrm{hr}$ were simulated corresponding to input velocity of 0.2 and $7.1 \mathrm{~mm} / \mathrm{s}$, respectively. The average values of shear stress in all the CCS for different microchannels were the same, Figure 5 .
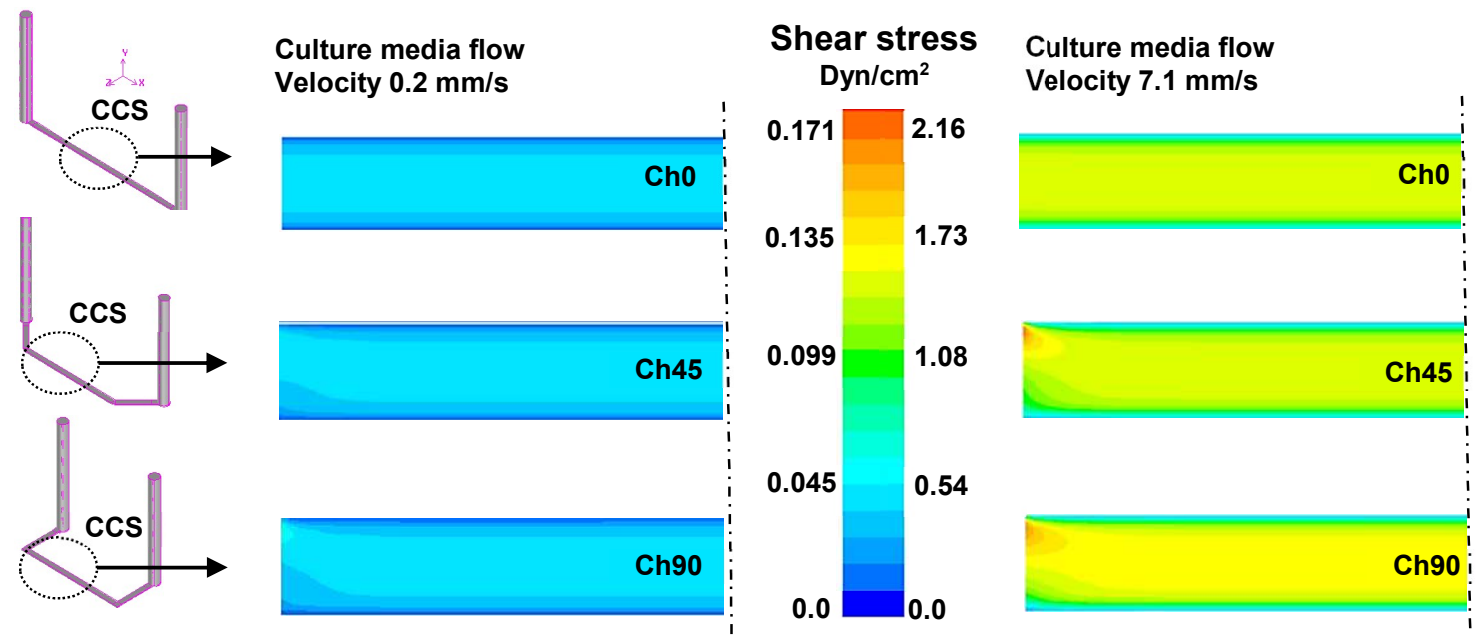

Figure 5: Distribution of shear stress on the cells in different channels for medium culture at two different values of inlet velocity (i.e., 0.2 and $7.1 \mathrm{~mm} / \mathrm{s}$ ).

The maximum velocities in the CCS, where the cells are embedded, are obtained as 0.56 and $29.11 \mathrm{~mm} / \mathrm{s}$ respectively. These values are higher than the capillary blood velocity, which was 
estimated to be $0.064 \mathrm{~mm} / \mathrm{s}$, based on the Horsfield's model [45]. To create a more realistic microenvironment, the speed of the blood or air in the vicinity of the cell should be considered which can be adjusted by changing the size, geometry and other mechanical parameters of the microchip. Distribution of the shear stress in different cross-sections of the microchannel Ch90 for culture media flow with a velocity of $7.1 \mathrm{~mm} / \mathrm{s}$ is shown in

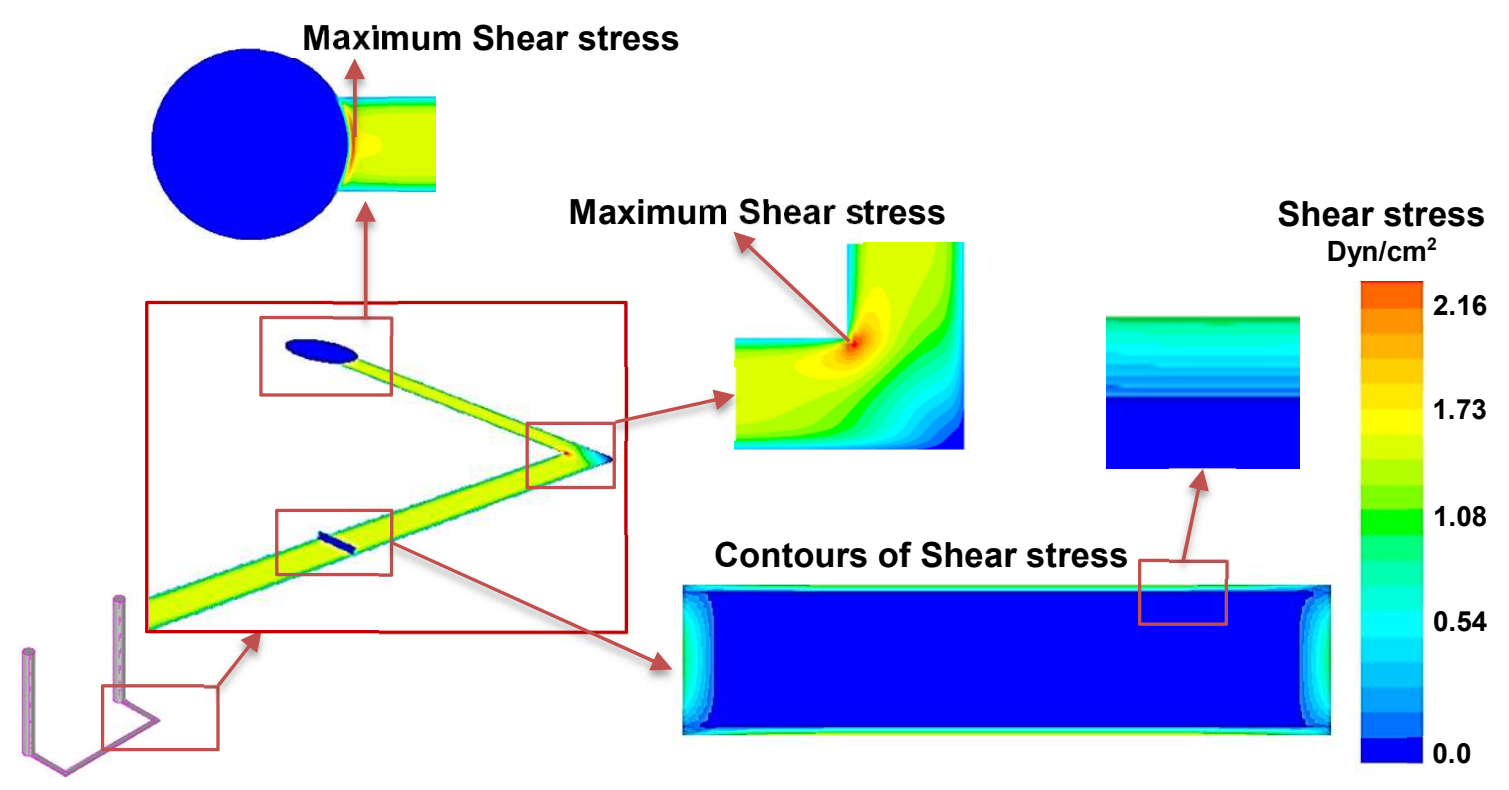

Figure 6. In a plane perpendicular to the flow direction in the CCS, maximum shear stress occurs on the walls. It decreases as the distance from the walls increases and becomes zero in the center line of the microchannel. In this plane, adherent cells to the wall receive the maximum shear stress, and suspended cells or particles are under lower shear stress. Although the average values of shear stress in all the CCS for different channels were the same, the maximum local stress differs in each microchannel, Error! Reference source not found. The maximum stress occurs where the flow turns sharply. Although it is far from the CCS, the cells can experience this high stress when they are being injected into the microchannels. As a result, the cells in the CCS may experience different initial conditions which in turn may affect the experimental outcomes and should be taken into account. 


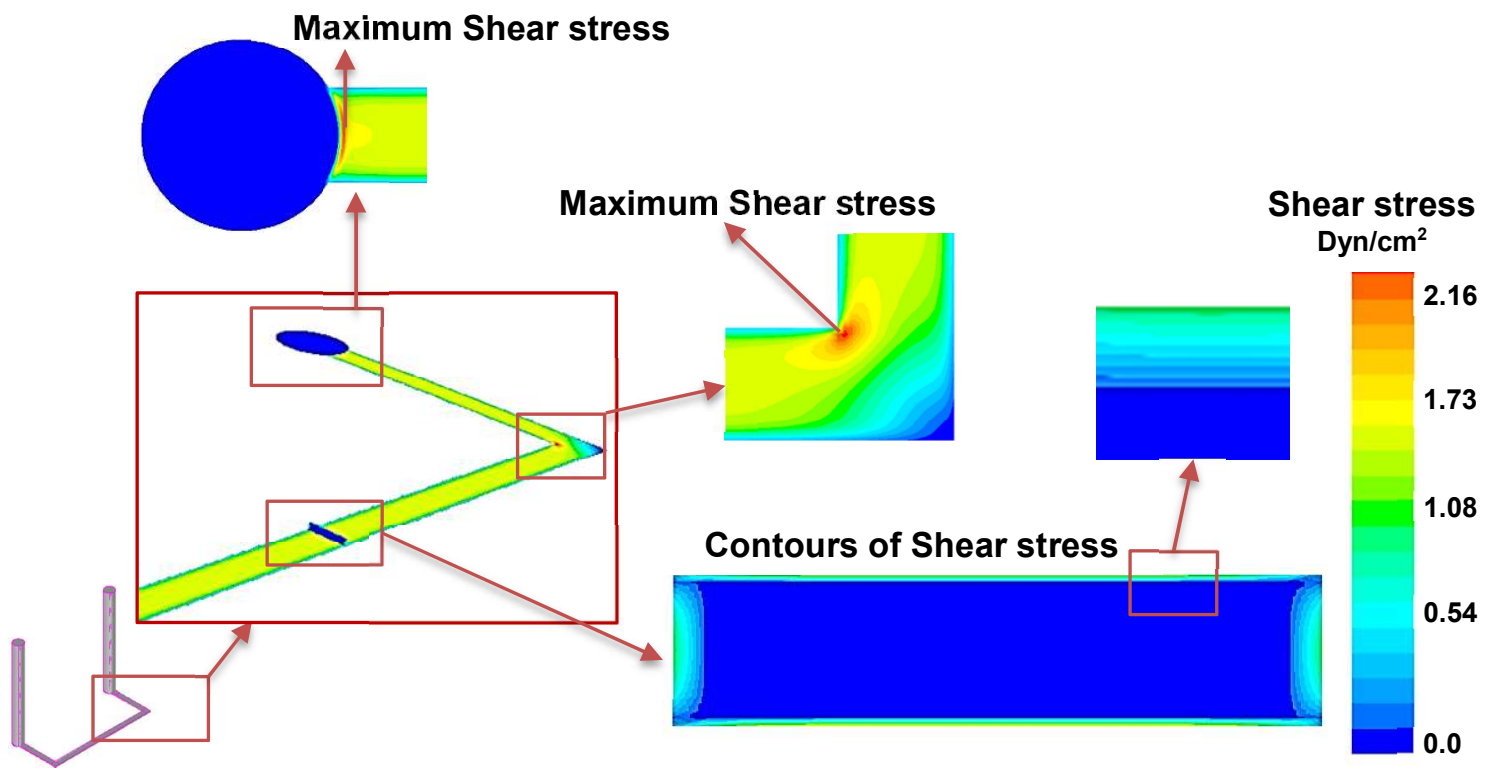

Figure 6: Distribution of the shear stress in different cross-sections of the microchannel Ch90 for culture media flow with a velocity of $7.1 \mathrm{~mm} / \mathrm{s}$. The schematic of Ch90, cross-section area containing CCS, maximum shear stress that occurs in the corner where the flow turns sharply and contours of shear stress in a cross-section perpendicular to the flow direction in the horizontal channel.

Data in Table 2 indicates that similar to the air flow, maximum local stress occurs in channel Ch90 which is almost 10 percent higher than that in the other microchannels. It is interesting to note that for all the flow rates in these ranges, the difference among the maximum local stress is almost 10 percent and does not depend on the flow rate. The maximum values of shear stress were 0.061 and $2.16 \mathrm{dyn} / \mathrm{cm}^{2}$ for the inlet velocity of 0.2 and $7.1 \mathrm{~mm} / \mathrm{s}$, respectively. These values are in the allowable range of $0.2-20 \mathrm{dyn} / \mathrm{cm}^{2}$ [43]. The flow rate of $100 \mu 1 / \mathrm{h}$ was also simulated which corresponded to the inlet velocity of $35.5 \mathrm{~mm} / \mathrm{s}$. The maximum shear stress of this high flow rate was $11.03 \mathrm{dyn} / \mathrm{cm}^{2}$ for the $\mathrm{Ch} 90$ which is still in the safe range of the shear stress for the cells. The high flow rate has more considerable drag and can to push the large micron particles into the microchannel which will be described in next section (Particle in culture media). 
Table 2: Channel Maximum shear stress

\begin{tabular}{cccc}
\hline & \multicolumn{3}{c}{ Maximum shear stress $\left(\mathrm{dyn} / \mathrm{cm}^{2}\right)$} \\
\cline { 2 - 4 } Sample & $0.56(\mu \mathrm{l} / \mathrm{h})$ & $20(\mu \mathrm{l} / \mathrm{h})$ & $100(\mu \mathrm{l} / \mathrm{h})$ \\
\hline Ch0 & 0.056 & 1.99 & 10.26 \\
\hline Ch45 & 0.056 & 2.01 & 10.51 \\
\hline Ch90 & 0.061 & 2.16 & 11.03 \\
\hline
\end{tabular}

\subsubsection{Cavity Flow}

In all the above microchannels, the cells were cultured in the horizontal plane of CCS, and flow passed through them horizontally. However, recent studies have proved that the streamline of the air in the alveolar sac is radial [46] which means that lung alveolar epithelial cells are under vertical flow during the breath. To create a model of radial flow over the cells, we designed a cavity at the bottom of the microchannel as the CCS as shown in Figure 7B The height of the microchannel is $100 \mu \mathrm{m}$ and the cavity has a dimension of $100 \times 1000 \times 1000 \mu \mathrm{m}$. The air flow field simulation for that case indicated that there was no significant vortex in the cavity due to the low flow velocity. Beside, radial streams are created only in a very small region at the corners of the cavity which is ignorable compared to the cavity floor area. In addition, the average shear stress in the cavity is approximately equal to that in a microchannel with $200 \mu \mathrm{m}$ height without cavity, Figure 7 and Table 3. The data in Table 3 indicates that for both values of the flow rate, the shear stress in the cavity with the height of $100 \mu \mathrm{m}$ connected to a $100 \mu \mathrm{m}$ height microchannel (abbreviated as Ch0-Cav100) is identical with the shear stress in a larger planar microchannel without cavity with a height of $200 \mu \mathrm{m}$ (abbreviated as Ch0-200mic). As illustrated in Figure 7, the height of the planar microchannel is equivalent to the sum of both cavity and microchannel heightFigure 7. The flow field of Ch0-Cav100 is almost identical with the flow field of Ch0200mic. Due to difficulties in both fabricating a microchannel with cavity and chemical sampling in small quantity, using a cavity with a rigid wall is not recommended as an in vitro model. 
Table 3: The average shear stress

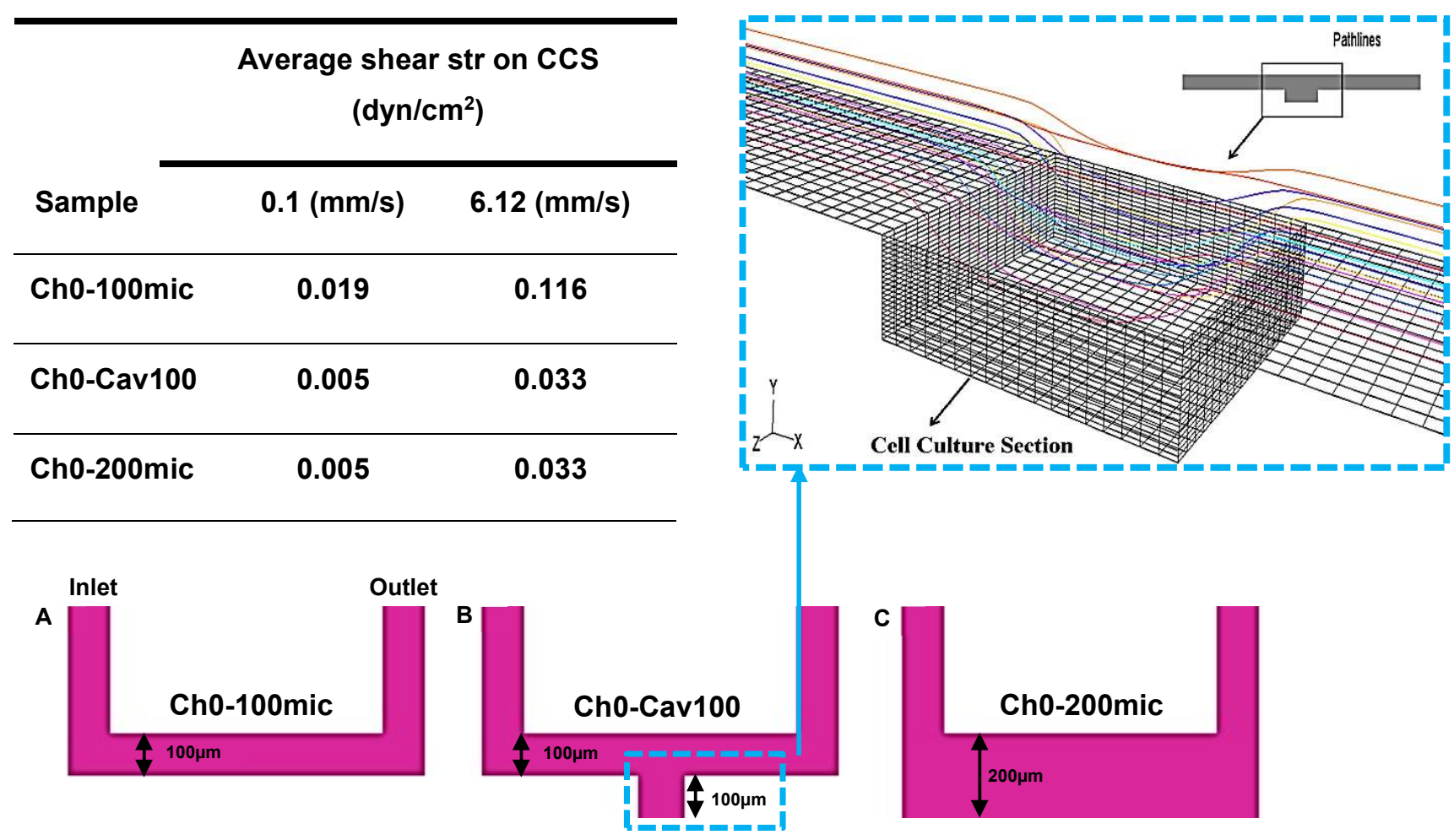

Figure 7: Cavity embedded in the microchannel. A) Ch0-100mic, the simple microchannel without cavity with a height of $100 \mu \mathrm{m}$. B) Ch0-Cav100, the microchannel with a cavity, the main microchannel has a height of $100 \mu \mathrm{m}$ and the cavity has a height of $100 \mu \mathrm{m}$. C) Ch0-200mic, the simple microchannel without cavity with a height of $200 \mu \mathrm{m}$.

\subsubsection{Particle deposition in air flow}

Researchers are interested in drug delivery using micro and nanoparticle as the drug carrier in the inhalers for the respiratory system [47]. In order to study aerosol behavior in a microchip, the air flow containing particles with different diameters were simulated numerically. Uniformly dispersed particles were released from the inlet surface into the flow, and then the amount and location of the particles deposition were investigated. Figure 8 demonstrates local deposition of particles with diameters of 1, 12,36, 100, 200 and $500 \mathrm{~nm}$ spreading in the air flow with a velocity of $0.1 \mathrm{~mm} / \mathrm{s}$. 


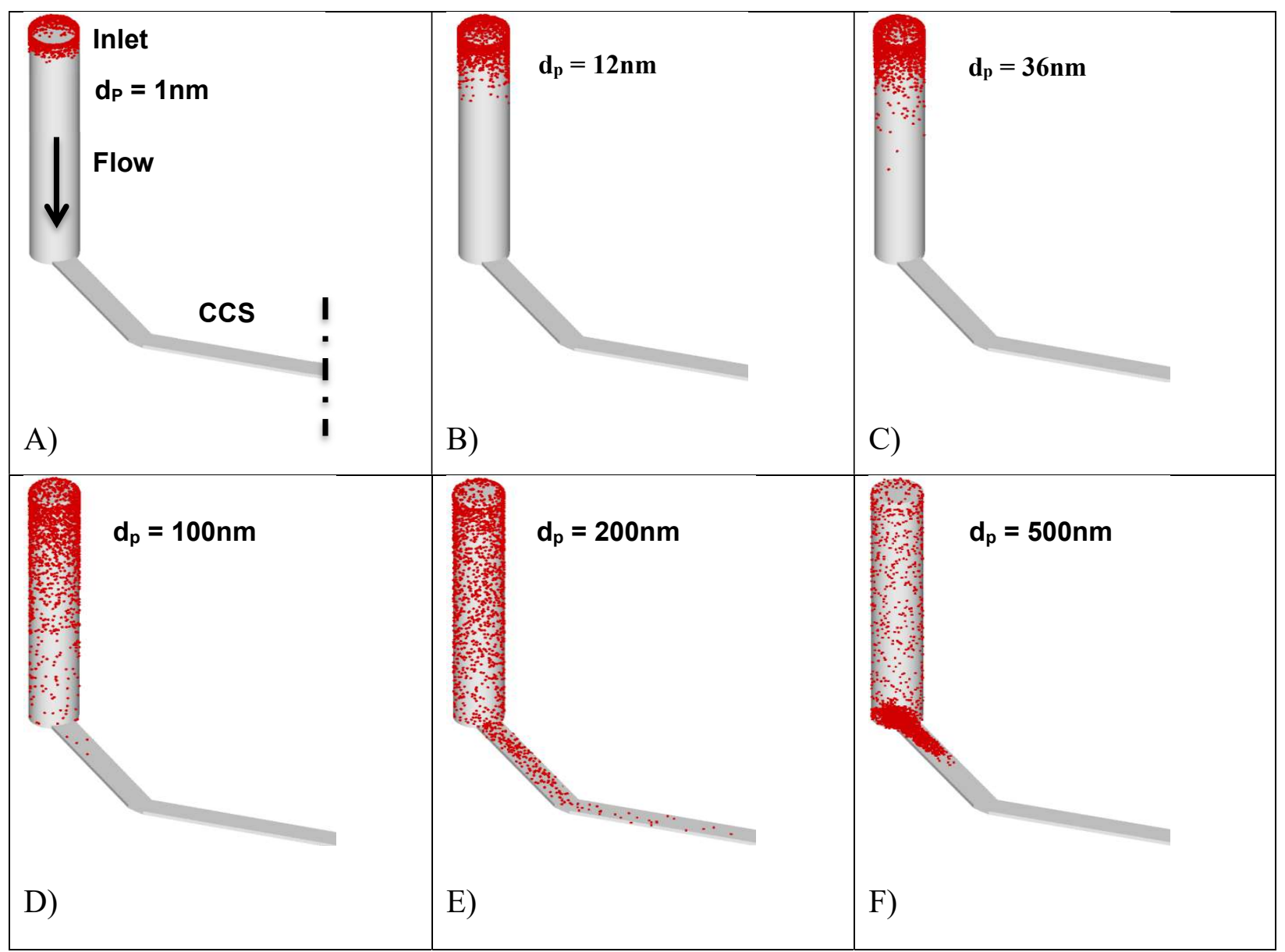

Figure 8: Deposition of particles with different diameters, $d_{p}$, at the air inlet velocity of $0.1 \mathrm{~mm} / \mathrm{s}$. A) All $1 \mathrm{~nm}$ particles are trapped in the wall near the inlet surface and do not penetrate to other regions. B) $12 \mathrm{~nm}$, C) $36 \mathrm{~nm}$ and D) $100 \mathrm{~nm}$ particles travel farther but they cannot arrive at the CCS. E) Only a small number of $200 \mathrm{~nm}$ reach the CCS. F) An acceptable number of $500 \mathrm{~nm}$ particles pass the cylindrical input but they cannot follow the flow $90^{\circ}$ turn in the conjunction to the horizontal channel and are trapped due to high inertia.

Although particle deposition efficiency of the microchannel was 100 percent for all particle diameters, only a handful of $200 \mathrm{~nm}$ particles could arrive at the CCS, Figure 8E. Small diffusion-dominant particles $(1,12,36$ and $100 \mathrm{~nm}$ particles) deposited at the beginning of the inlet because the flow drag cannot overcome their diffusion. Consequently, they cannot reach the CCS, Figure 8A-D. A small portion of the large particles (500 nm particles) was deposited by diffusion on the vertical wall of the inlet cylinder. These particles were bringing with the streamline near the wall. The remaining particles were trapped at the bottom of the cylindrical inlet where the flow turns $90^{\circ}$, Figure $8 \mathrm{~F}$. Because of high inertia of the large particles, they were unable to follow the flow and reach the CCS. Where the flow direction changes dramatically, the inertia of the 
particle dominants the drag of the flow and particles are not able to follow the flow and will be trapped on the wall. Particles with diameters of 1,3 and 5 microns were also modeled that behaved similarly to $500 \mathrm{~nm}$ particles (data not shown). To deliver the particles to the CCS, a higher flow rate corresponding to inlet velocity of $0.612 \mathrm{~mm} / \mathrm{s}$ was simulated. Increasing flow velocity overcame the diffusion of the small particles (1, 12, 36,100 and 200-nm particles which is diffusion-dominant particles) and pushed them to the deeper regions so that approximately $98 \%$ of $200 \mathrm{~nm}$ particles and $88 \%$ of $100 \mathrm{~nm}$ particles reach the CCS as shown in Figure 9. However, increasing the flow velocity increased the particle inertia and the larger particles $(500 \mathrm{~nm}, 1,3$ and $5 \mu \mathrm{m})$ with dominant inertia were not able to reach the CCS, and they were trapped in the conjunction of the vertical cylinder to the horizontal microchannel, as illustrated in Figure 8F.

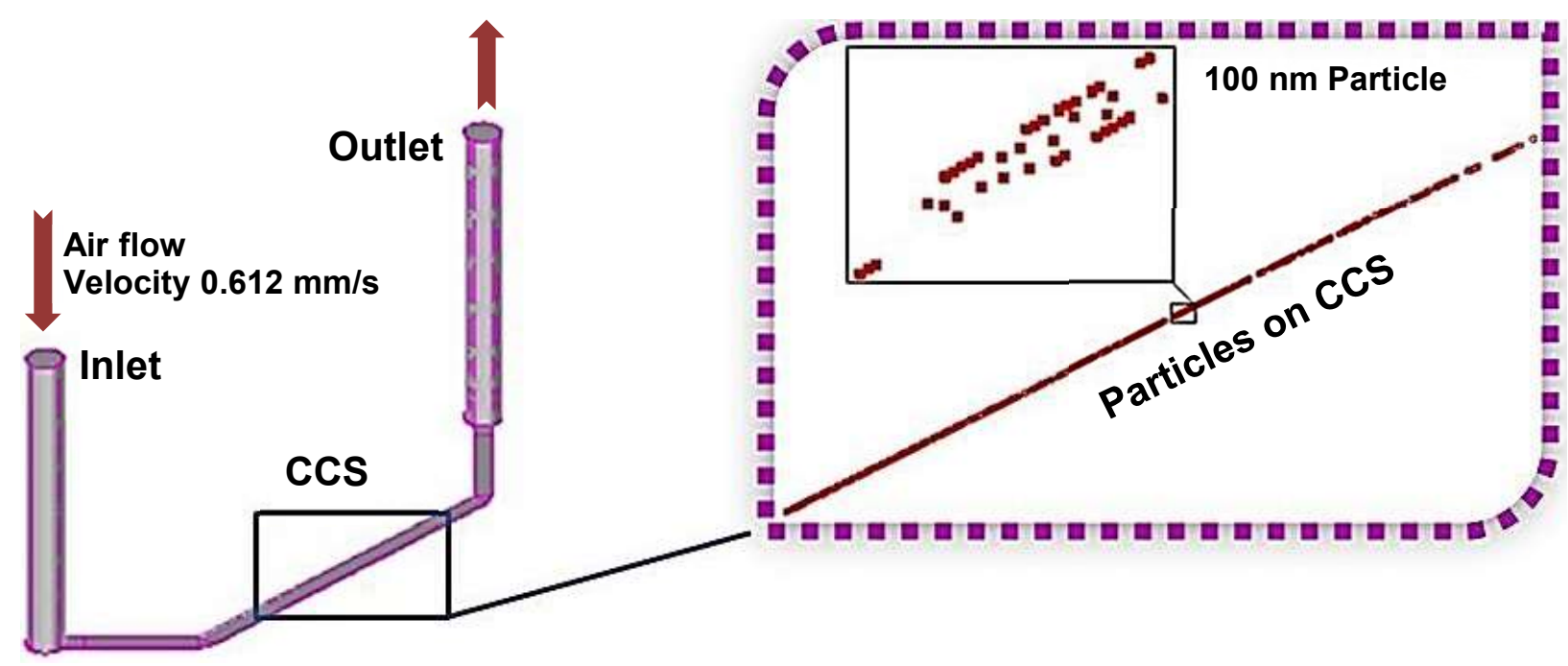

Figure 9: $100 \mathrm{~nm}$ particles in the air flow with the velocity inlet of $0.612 \mathrm{~mm} / \mathrm{s}$. Increasing the flow velocity pushed particle to the CCS and approximately $88 \%$ of $100 \mathrm{~nm}$ particles deposited on CCS.

The results suggest that the deposition efficiency of the channel is almost $100 \%$ for all particles. However, in the first case with the inlet velocity of $0.1 \mathrm{~mm} / \mathrm{s}$, none of the $100 \mathrm{~nm}$ particles reached the CCS. By increasing the inlet velocity to $0.612 \mathrm{~mm} / \mathrm{s}, 88 \%$ of $100 \mathrm{~nm}$ particles deposited in the CCS. In the experiment, it is important to deliver the particle to the cells to evaluate the toxicity or therapy effect of the particle. For example, if $100 \mathrm{~nm}$ toxic particles are introduced to the cells cultured in the microchannel using the air inlet velocity of $0.1 \mathrm{~mm} / \mathrm{s}$, all the $100 \mathrm{~nm}$ particles will be deposited in the microchannel, and the escaping particles from the outlet will be 
zero. However, in that case, none of the particles can reach the cells on the CCS. Consequently, there must have been no toxic effect on the cells since they do not receive any toxic particles. Therefore, a misinterpretation might have happened, i.e., concluding nontoxicity for the introduced $100 \mathrm{~nm}$ particles while they are naturally toxic. Conversely, the injected $100 \mathrm{~nm}$ toxic particles by a higher air flow of $0.612 \mathrm{~mm} / \mathrm{s}$ would have revealed the toxic effect of them on the cell because in this condition most of the particles could have reached the CCS. Our numerical results recommend that to more accurately evaluate the effect of aerosol delivery to cells, particle behavior should be simulated and appropriate air flow rate should be estimated first.

The simulation results can also estimate the time that a given number of particles can be trapped on the walls or escape from the outlet. Table 4 indicates that the time for different particles is a function of particle diameter as well as the flow rate. In a constant flow rate, smaller particles deposit faster than larger ones because of their faster random motion in the air. For a given particle size, increasing the flow rate will result in increasing the drag force of the flow on the particle and push them to the horizontal microchannel where the dimension is small (compared to that of the inlet cylinder), and they are trapped on the wall faster. The inlet cylinder has a diameter of $1 \mathrm{~mm}$ and its volume is much larger than the horizontal microchannel. Therefore, most of the particles are far away from the wall in the inlet cylinder, and the particles need more time to reach the surrounding wall. For the inlet velocity of $0.1 \mathrm{~mm} / \mathrm{s}$, the particles remain suspended in the flow for a longer time while they travel a shorter distance in the vertical cylinder, Figure 8 . That is mainly because in such low air flow, the particle deposition is dominated by the diffusion. Whereas increasing the inlet velocity to $0.612 \mathrm{~mm} / \mathrm{s}$ can force particles to penetrate to the horizontal microchannel and increase the rate of their deposition.

Table 4: The time it takes to reach all the particles from the inlet to the beginning of CCS.

a) Inlet velocity $V=0.1(\mathrm{~mm} / \mathrm{s})$

\begin{tabular}{cc}
\hline Particle diameter $(\mathrm{nm})$ & Time (s) \\
\hline $100 \mathrm{~nm}$ & 34 \\
$200 \mathrm{~nm}$ & 42
\end{tabular}

b) Inlet velocity $V=0.612(\mathrm{~mm} / \mathrm{s})$

\begin{tabular}{cc}
\hline Particle diameter $(\mathrm{nm})$ & Time(s) \\
\hline $100 \mathrm{~nm}$ & 12 \\
$200 \mathrm{~nm}$ & 15
\end{tabular}


Increasing the air flow rate can push the diffusion-dominant particles to reach the CCS. However, the airflow is not able to carry the inertia-dominant particles to reach the CCS. Therefore, a liquid phase such as culture media should be used to carry larger particles to the cells. The reason is that the drag of the liquid flow is larger than that of the air flow while the diffusion of the particles is smaller in the liquid flow compared with that in the air flow.

\subsubsection{Particle deposition in culture media}

From an experimental perspective, particles are commonly suspended in a liquid material such as culture media, and then the suspension will be injected into the microchannels [9]. In this paper, suspension of particles in culture media with various particle sizes in different values of flow rate was simulated numerically. The behavior of particles and their local and total deposition strongly depend on the flow rate of culture media and particle diameter. As demonstrated in Figure 10 , for the inlet velocity of $0.2 \mathrm{~mm} / \mathrm{s}$, a large number of small particles $(\mathrm{d} \leq 700 \mathrm{~nm})$ are aligned with the streamlines and carried with the flow and discharged from the outlet. In this case, the drag of the flow is dominant to the diffusion of the particle, and consequently, they travel with the flow, Figure 10. Only a small number of the particles, which are aligned on the streamlines near the walls, are trapped on the wall as the flow turns sharply in the conjunctions of the horizontal channel with the vertical inlet and outlet cylinders, Figure 10. Under such circumstances, continuous flow pushes most of the suspended particles to the outlet port and particle deposition is very low compared with the injected particles. To increase the particle deposition, in experiment, after injecting particle suspension into microchannel, the flow will be shut off to allocate a time so that the particles can settle down on the cells [9]. To model that condition, the particles were released from two vertical and horizontal planes as shown in Figure 11 and Figure 12. It is assumed that the flow is stagnant, and the particles have the initial velocity of the fluid flow where they were initially located. For example, all of the $700 \mathrm{~nm}$ particles located in a vertical plane were deposited in less than 5 seconds, Figure 11. Most of the particles initially located in the horizontal plane on top of the horizontal microchannel are settled under the floor due to gravity, Figure 12. Only a small number of the particles near the outlet cylinder follow the path line to go out. These particles are negligible compared to the deposited particles. For large particles $(\mathrm{d} \geq 1 \mu \mathrm{m})$, the drag of the flow of the inlet velocity of $0.2 \mathrm{~mm} / \mathrm{s}$ is not able to push the particle out of the microchannel. As 
illustrated in Figure 13, larger particles $(1,2$ and $4 \mu \mathrm{m})$ are trapped in the earlier region of the microchannel, and only small amount of $1 \mu \mathrm{m}$ particle can reach the CCS. Therefore, larger particles $(d \geq 2 \mu \mathrm{m})$ are not able to reach the CCS with a velocity inlet of $0.2 \mathrm{~mm} / \mathrm{s}$. To carry larger particles in the microchannel, the inlet velocity should be increased to increase the flow drag on the particles and drive them to the CCS. For example, $5 \mu \mathrm{m}$ particles are carried with the flow with the inlet velocity of $7.1 \mathrm{~mm} / \mathrm{s}$ that behaved similarly to $700 \mathrm{~nm}$ particles in the flow with inlet velocity of $0.2 \mathrm{~mm} / \mathrm{s}$, Figure 10 . The result indicated that both particle diameter and the flow rate should be adjusted to carry a desirable number of the particles to the CCS. Thus, for drug delivery assay, the flow rate must be adjusted according to the available particle size to maximize particle deposition on cells. 


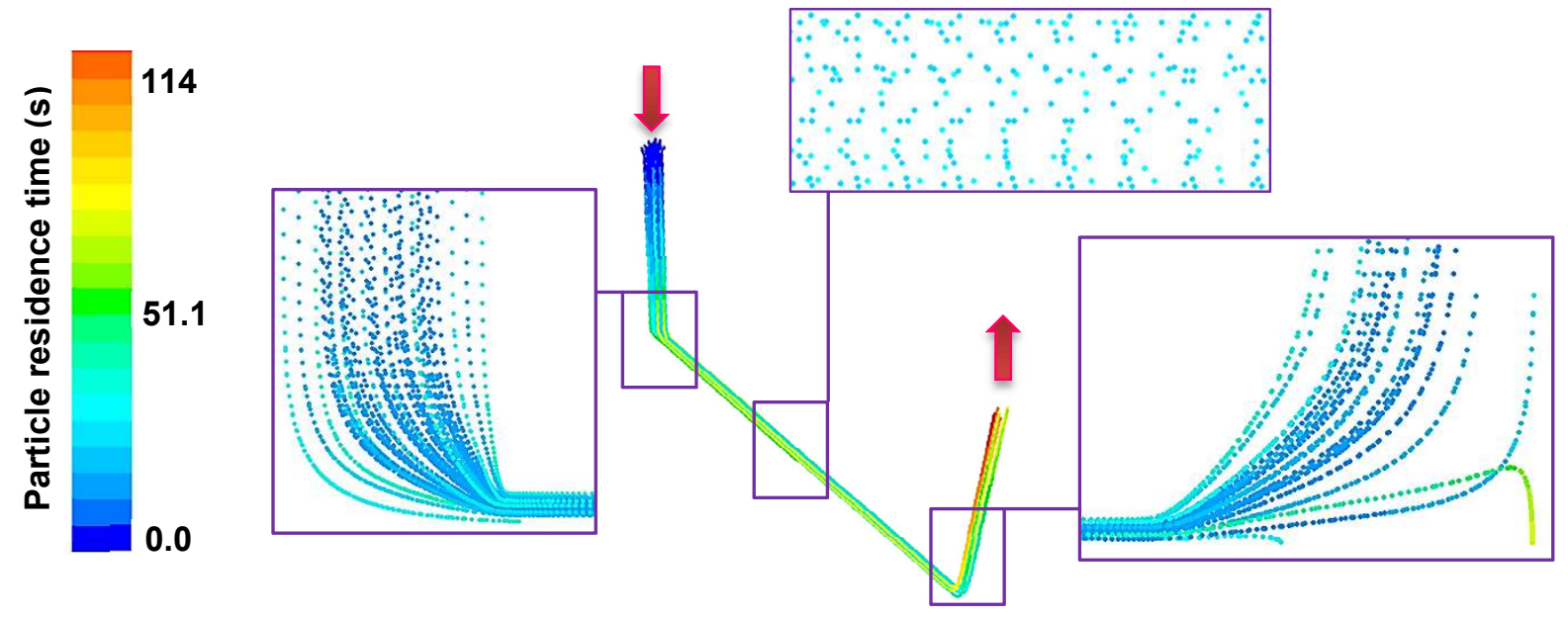

Figure 10: For the inlet velocity of $0.2 \mathrm{~mm} / \mathrm{s}$ a large number of small particles $(\mathrm{d} \leq 700 \mathrm{~nm})$ are aligned on the streamlines and carried with the flow and discharged from the outlet.
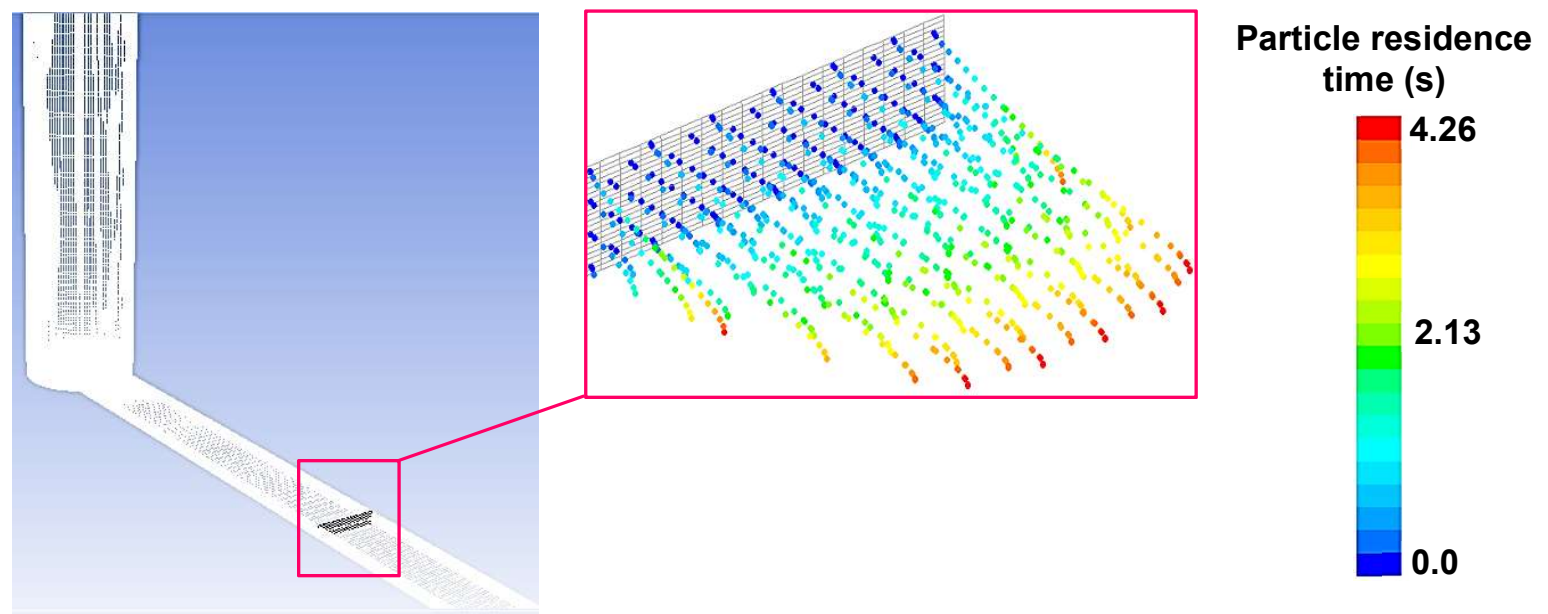

Figure 11: The $700 \mathrm{~nm}$ particles were released from a vertical plane and all of them were deposited in less than 5 seconds. The initial velocity of the released particles was equal to the flow field corresponding to the inlet velocity of $0.2 \mathrm{~mm} / \mathrm{s}$. 


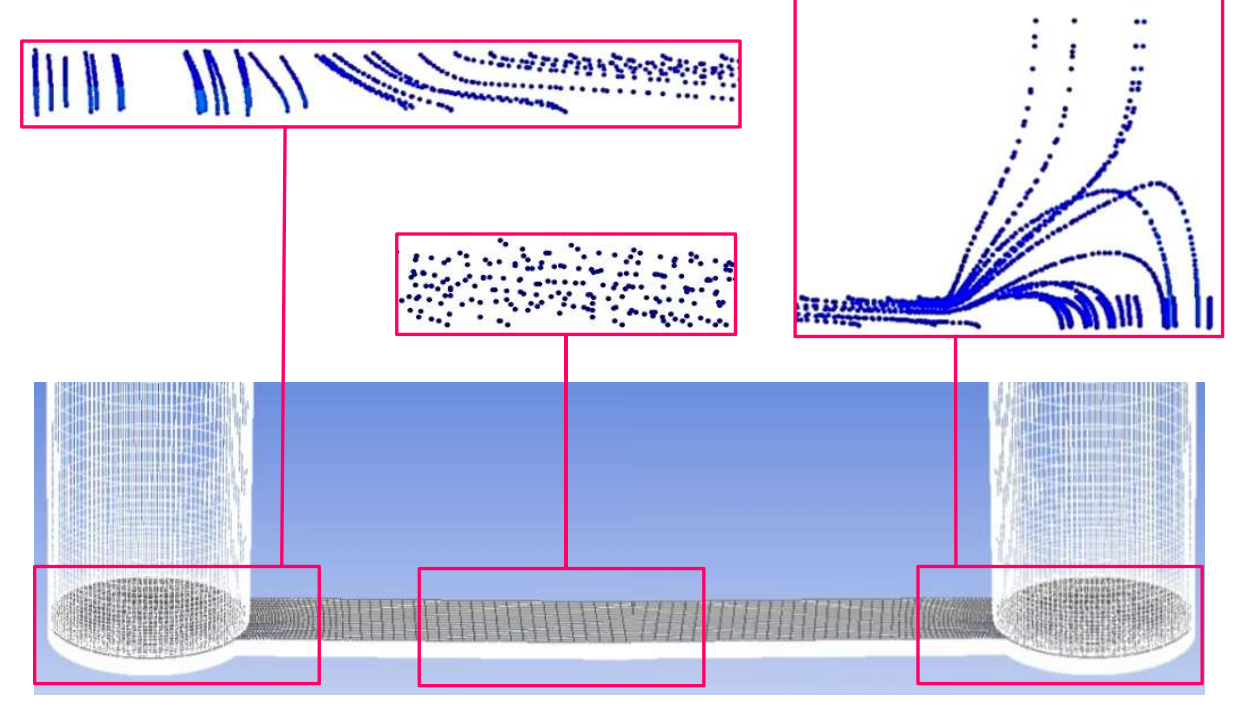

Figure 12: Local deposition of the $700 \mathrm{~nm}$ particles released from a horizontal plane (shown in dark color). The initial velocity of the released particles was equal to the flow field corresponding to the inlet velocity of $0.2 \mathrm{~mm} / \mathrm{s}$.

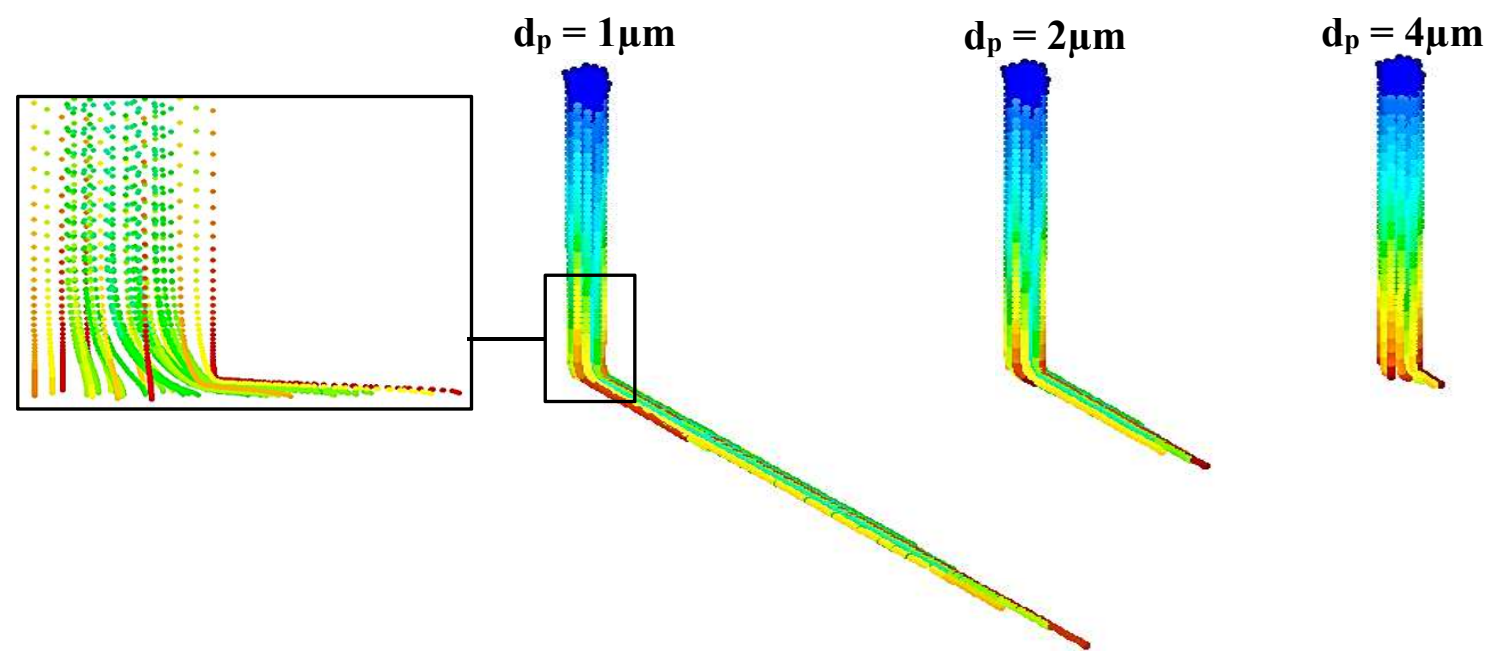

Figure 13: large particles $(d \geq 2 \mu \mathrm{m})$ are trapped in the earlier region and they are not able to reach the CCS. 


\subsection{Experimental study}

Our numerical simulations show that although the airflow is not able to transport large particle $(\mathrm{d} \geq 1 \mu \mathrm{m})$ to the CCS, the medium culture flow can bring large particle $(\mathrm{d} \geq 1 \mu \mathrm{m})$ to the CCS. As an experimental model, lung cancer cell line (A549) and ink particles as the micron-size particles (5 and $20 \mu \mathrm{m}$, respectively) were suspended in the culture media, and then were injected into the microchannel by a syringe pump, Figure 14A. The suspension of lung cancer cell line (A549) in culture media was perfused to the microchip with the flow rate of $20 \mu 1 / \mathrm{hr}$ corresponding to the inlet velocity of $7.1 \mathrm{~mm} / \mathrm{s}$. When the flow was observed in the outlet port, the pump was switched off, and the microchannel was observed under an optical invert microscope, Figure 14B. A549 cells are particles with an approximately $5 \mu \mathrm{m}$ diameter when they are suspended in a liquid. As in our numerical simulation, it was shown that the inlet velocity of $7.1 \mathrm{~mm} / \mathrm{s}$ is able to bring large inertia-dominant particle to the CCS. This case was chosen to validate our numerical results. Figure $14 \mathrm{C}$ demonstrates a uniform distribution of A549 cells in the CCS. The living cells are really loose so they do not stick to each other or to the walls, and they reach the CCS with their initial concentration. Using the same experimental set-up, in another experiment, the ink particles with larger diameters (around $20 \mu \mathrm{m}$ ) were diluted in the culture media and then injected into the microchannel with the flow rate of $20 \mu \mathrm{l} / \mathrm{hr}$, Figure 14D. In accordance with our numerical simulation, the ink particles (whose diameters are more than $1 \mu \mathrm{m}$ ) could reach the CCS of the microchip. The experimental results showed that most of these particles penetrated to the CCS while some of them were trapped in the initial regions, and some others accumulated to each other and formed lager particle $(50 \mu \mathrm{m})$. In our simulation, the accumulation of the particle was ignored. It can be taken into account to mimic a more realistic situation of sticky particles as a future work. The experimental data validated our numerical simulation for the large inertia dominant particle.

Experimental tracking of smaller particles (i.e., nanoparticles) is costly and requires sophisticated instrument which are not available in most laboratories. This signifies the importance of conducting numerical simulation for nanoparticle tracking. 
A

B

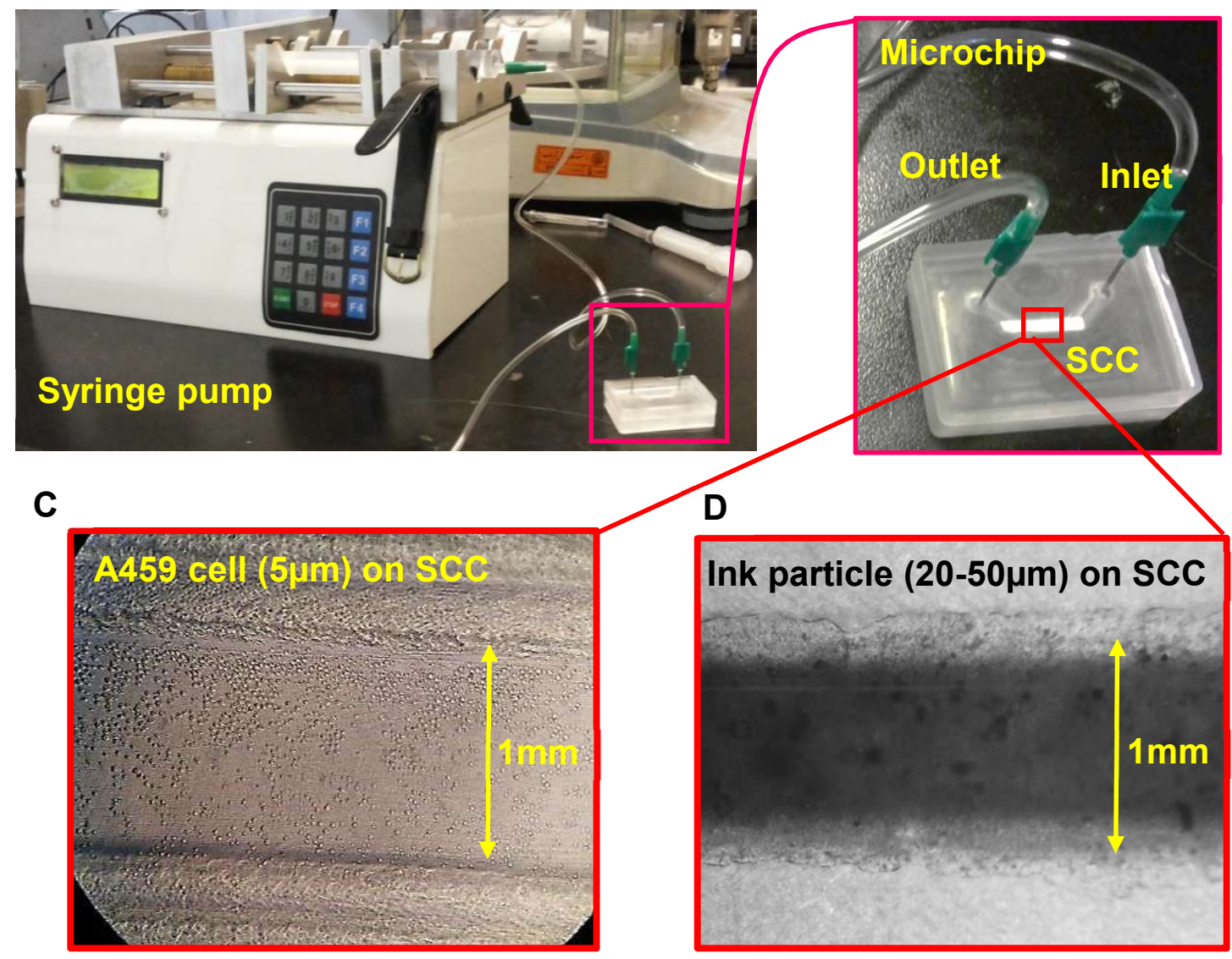

Figure 14: a) The microchip was connected to a syringe pump. b) The enlarged view of the microchip which shows the inlet and outlet ports and CCS, c) A549 cell $(5 \mu \mathrm{m})$ in CCS and d) ink particle (20-50 $\mu \mathrm{m})$ in CCS

\section{Conclusion}

The flow field of the microchannels of lung-on-chip microdevices was simulated for the flow of air and medium culture under different flow rates. We evaluated the impact of various geometrical parameters including the different angles of the connection inlet to the cell culture section on the flow field and the shear stress distribution on the microchannel. Next, we simulated nano and microparticle deposition inside the microchannel under various conditions. The numerical results were experimentally validated by microparticle transport to the fabricated microchannel by medium culture as the carrier. 
The flow field simulation indicated that for a given mass flow rate, uniform and equal shear stress distribution occurred in the cells on the cell culture section in both air and medium culture flow. Although the shear stress on the cell culture section was the same, the local shear stress was different in various microchips. The maximum local shear stress occurred in the microchannel with $90^{\circ}$ connection angles where the flow turns sharply as the geometry of the microchannel changed. Although that site is far from the cell culture section, high local shear stress can damage the suspended cells before reaching the cell culture section. As a result, our simulation emphasizes that prior to experimentally introducing the cell suspension into a microfluidic device, the values of local shear stress must be taken into account by the aid of computational fluid dynamic simulation to keep the cells safe and healthy during cell seeding into microdevice. Particle modeling demonstrated that the number and the location of the trapped particles were a function of the flow rate and the particle diameter. For a given air flow rate, the overall particle deposition efficiency of the microchannel was $100 \%$ for all particles while the local particle deposition was completely different. In other words, although all the particles were trapped in the microchannel and none of them was observed in the outlet, only a small portion of them could reach the cell, and most of them were deposited in the entrance regions. For the aerosol, the high flow rate of air can transport the small diffusion-dominant particles $(\mathrm{d} \leq 700 \mathrm{~nm})$ to the cells. However, the airflow is not able to bring large inertia particles $(\mathrm{d} \geq 1 \mu \mathrm{m})$ to the cell culture section. By optimizing the flow rate and the size and shape of the microchannels, the desired number of particles can be delivered to the cells. Nevertheless, large aerosols with micron-size diameters cannot reach the cell culture section even at high air flow rates. The numerical simulation demonstrated that the large inertia particles could reach the cells by using a liquid flow carrier. The experimental results for the large micron-size particles suspended in a liquid proved that the liquid flow was able to bring large micron-size particles to the cell culture section. Thus, a liquid carrier is suggested for large particles to deliver cells in microchips. Precise nanoparticle tracking requires expensive experimental set-up. However, numerical simulation provides a nearly complete understanding of the flow field and the patterns of particle deposition in microchips. It can significantly lower the trial and error of the experiment tests and accordingly save considerable cost and time for drug delivery in the cell culture microdeviecs in drug screening assay.

Conflicts of Interest: The authors declare no conflict of interest. 


\section{References}

.1 Nguyen, N.-T., Shaegh, S.A.M., Kashaninejad, N., and Phan, D.-T., Design, fabrication and characterization of drug delivery systems based on lab-on-a-chip technology. Advanced drug delivery reviews, 2013. 65(11): p. 1403-1419.

.2 Kashaninejad, N., Nikmaneshi, M.R., Moghadas, H., Kiyoumarsi Oskouei, A., Rismanian, M., Barisam, M., Saidi, M.S., and Firoozabadi, B., Organ-Tumor-on-a-Chip for Chemosensitivity Assay: A Critical Review. Micromachines, 2016. 7(8): p. 130.

.3 Nguyen, N.-T., Hejazian, M., Ooi, C.H., and Kashaninejad, N., Recent Advances and Future Perspectives on Microfluidic Liquid Handling. Micromachines, 2017. 8(6): p. 186.

.4 Moghadas, H., Saidi, M.S., Kashaninejad, N., Kiyoumarsioskouei, A., and Nguyen, N.T., Fabrication and characterization of low-cost, bead-free, durable and hydrophobic electrospun membrane for $3 D$ cell culture. Biomedical Microdevices, 2017. 19(4): p. 74.

.5 Levy, R., Hill, D.B., Forest, M.G., and Grotberg, J.B., Pulmonary Fluid Flow Challenges for Experimental and Mathematical Modeling. Integrative and comparative biology, 2014. 54(6): p. 985-1000.

.6 Tavana, H., Kuo, C.-H., Lee, Q.Y., Mosadegh, B., Huh, D., Christensen, P.J., Grotberg, J.B., and Takayama, S., Dynamics of liquid plugs of buffer and surfactant solutions in a micro-engineered pulmonary airway model. Langmuir, 2009. 26(5): p. 3744-3752.

.7 Douville, N.J., Zamankhan, P., Tung, Y.-C., Li, R., Vaughan, B.L., Tai, C.-F., White, J., Christensen, P.J., Grotberg, J.B., and Takayama, S., Combination of fluid and solid mechanical stresses contribute to cell death and detachment in a microfluidic alveolar model. Lab on a chip, 2011. 11(4): p. 609-619.

.8 Huh, D., Matthews, B.D., Mammoto, A., Montoya-Zavala, M., Hsin, H.Y., and Ingber, D.E., Reconstituting organ-level lung functions on a chip. Science, 2010. 328(5986): p. 1662-1668.

.9 Huh, D., Leslie, D.C., Matthews, B.D., Fraser, J.P., Jurek, S., Hamilton, G.A., Thorneloe, K.S., McAlexander, M.A., and Ingber, D.E., A human disease model of drug toxicityinduced pulmonary edema in a lung-on-a-chip microdevice. Science translational medicine, 2012. 4(159): p. 159ra147.

.10 Rothen-Rutishauser, B.M., Kiama, S.G., and Gehr, P., A three-dimensional cellular model of the human respiratory tract to study the interaction with particles. American journal of respiratory cell and molecular biology, 2005. 32(4): p. 281-289. 
.11 Howell, M., Wang, C., Mahmoud, A., Hellermann, G., Mohapatra, S., and Mohapatra, S., Dual-function theranostic nanoparticles for drug delivery and medical imaging contrast: perspectives and challenges for use in lung diseases. Drug delivery and translational research, 2013. 3(4): p. 352-363.

.12 Hittinger, M., Juntke, J., Kletting, S., Schneider-Daum, N., de Souza Carvalho, C., and Lehr, C.-M., Preclinical safety and efficacy models for pulmonary drug delivery of antimicrobials with focus on in vitro models. Advanced drug delivery reviews, 2015. 85 : p. 44-56.

.13 Moghadas, H., Abouali, O., Faramarzi, A., and Ahmadi, G., Numerical investigation of septal deviation effect on deposition of nano/microparticles in human nasal passage. Respiratory physiology \& neurobiology, 2011. 177(1): p. 9-18.

.14 Nagy, A., Steinbrück, A., Gao, J., Doggett, N., Hollingsworth, J.A., and Iyer, R., Comprehensive analysis of the effects of CdSe quantum dot size, surface charge, and functionalization on primary human lung cells. Acs Nano, 2012. 6(6): p. 4748-4762.

.15 Blank, F., Rothen-Rutishauser, B.M., Schurch, S., and Gehr, P., An optimized in vitro model of the respiratory tract wall to study particle cell interactions. Journal of Aerosol Medicine, 2006. 19(3): p. 392-405.

.16 Sera, T., Uesugi, K., Yagi, N., and Yokota, H., Numerical simulation of airflow and microparticle deposition in a synchrotron micro-CT-based pulmonary acinus model. Computer methods in biomechanics and biomedical engineering, 2015. 18(13): p. 14271435.

.17 Pourmehran, O., Rahimi-Gorji, M., Gorji-Bandpy, M., and Gorji, T., Simulation of magnetic drug targeting through tracheobronchial airways in the presence of an external non-uniform magnetic field using Lagrangian magnetic particle tracking. Journal of Magnetism and Magnetic Materials, 2015. 393: p. 380-393.

.18 Bailey, M.M. and Berkland, C.J., Nanoparticle formulations in pulmonary drug delivery. Medicinal research reviews, 2009. 29(1): p. 196-212.

.19 Mishra, D.K., Dhote, V., Bhatnagar, P., and Mishra, P.K., Engineering solid lipid nanoparticles for improved drug delivery: promises and challenges of translational research. Drug delivery and translational research, 2012. 2(4): p. 238-253.

.20 Nagel, T., Resnick, N., Dewey, C.F., and Gimbrone, M.A., Vascular endothelial cells respond to spatial gradients in fluid shear stress by enhanced activation of transcription factors. Arteriosclerosis, Thrombosis, and Vascular Biology, 1999. 19(8): p. 1825-1834. 
.21 Legant, W.R., Miller, J.S., Blakely, B.L., Cohen, D.M., Genin, G.M., and Chen, C.S., Measurement of mechanical tractions exerted by cells in three-dimensional matrices. Nature methods, 2010. 7(12) :p. 969-971.

.22 Huang, S., Chen, C.S., and Ingber, D.E., Control of cyclin D1, p27Kip1, and cell cycle progression in human capillary endothelial cells by cell shape and cytoskeletal tension. Molecular biology of the cell, 1998. 9(11): p. 3179-3193.

.23 McBeath, R., Pirone, D.M., Nelson, C.M., Bhadriraju, K., and Chen, C.S., Cell shape, cytoskeletal tension, and RhoA regulate stem cell lineage commitment. Developmental cell, 2004. 6(4): p. 483-495.

.24 Wang, H., Riha, G.M., Yan, S., Li, M., Chai, H., Yang, H., Yao, Q., and Chen, C., Shear stress induces endothelial differentiation from a murine embryonic mesenchymal progenitor cell line. Arteriosclerosis, thrombosis, and vascular biology, 2005. 25(9): p. 1817-1823.

.25 Young, E.W., Wheeler, A.R., and Simmons, C.A., Matrix-dependent adhesion of vascular and valvular endothelial cells in microfluidic channels. Lab on a Chip, 2007. 7(12): p. 1759-1766.

.26 Shamloo, A., Ma, N., Poo, M.-m., Sohn, L.L., and Heilshorn, S.C., Endothelial cell polarization and chemotaxis in a microfluidic device. Lab on a chip, 2008. 8(8): p. 12921299.

.27 Kim, M.-g., Kim, Y.-H., Kim, H.-L., Park, C.W., Joe, Y.-H., Hwang, J., and Kim, Y.-J., Wall loss reduction technique using an electrodynamic disturbance for airborne particle processing chip applications. Journal of Micromechanics and Microengineering, 2010. 20(3): p. 035034.

.28 Sriphutkiat, Y. and Zhou, Y., Particle Accumulation in a Microchannel and Its Reduction by a Standing Surface Acoustic Wave (SSAW). Sensors, 2017. 1 :(1)7p. 106.

.29 Porter, B., Zauel, R., Stockman, H., Guldberg, R., and Fyhrie, D., 3-D computational modeling of media flow through scaffolds in a perfusion bioreactor. Journal of biomechanics, 2005. 38(3): p. 543-549.

.30 Singh, H., Teoh, S.-H., Low, HT., and Hutma.cher, D., Flow modelling within a scaffold under the influence of uni-axial and bi-axial bioreactor rotation. Journal of biotechnology, 2005. 119(2): p. 181-196.

.31 Cioffi, M., Boschetti, F., Raimondi, M.T., and Dubini, G., Modeling evaluation of the fluid-dynamic microenvironment in tissue-engineered constructs: A micro-CT based model. Biotechnology and bioengineering, 2006. 93(3): p. 500-510. 
.32 Boschetti, F., Raimondi, M.T., Migliavacca, F., and Dubini, G., Prediction of the microfluid dynamic environment imposed to three-dimensional engineered cell systems in bioreactors. Journal of biomechanics, 2006. 39(3): p. 418-425.

.33 Galbusera, F., Cioffi, M., Raimondi, M., and Pietrabissa, R., Computational modeling of combined cell population dynamics and oxygen transport in engineered tissue subject to interstitial perfusion. Computer methods in biomechanics and biomedical engineering, 2007. 10(4): p. 279-287.

.34 Raimondi, M.T., Bridgen, D.T., Laganà, M., Tonnarelli, B., Cioffi, M., Boschetti, F., and Wendt, D., Integration of experimental and computational microfluidics in $3 D$ tissue engineering. Methods in Bioengineering 3D Tissue Engineering. F. Berthiaume and. J Morgan Eds. Book series: Methods in Bioengineering (MIB), Yarmush ML and Langer RS Eds, Boston: Artech House, 2010: p. 237-242.

.35 Sellgren, K.L., Butala, E.J., Gilmour, B.P., Randell, S.H., and Grego, S., A biomimetic multicellular model of the airways using primary human cells. Lab on a Chip, 2014. 14(17): p. 3349-3358.

.36 Huh, D., Hamilton, G.A., and Ingber, D.E., From 3D cell culture to organs-on-chips. Trends in cell biology, 2011. 21(12): p. 745-754.

.37 Raimondi, M., Boschetti, F., Falcone, L., Fiore, G., Remuzzi, A., Marinoni, E., Marazzi, M., and Pietrabissa, R., Mechanobiology of engineered cartilage cultured under a quantified fluid-dynamic environment. Biomechanics and modeling in mechanobiology, 2002. 1(1): p. 69-82.

.38 Ferrell, N., Desai, R.R., Fleischman, A.J., Roy, S., Humes, H.D., and Fissell, W.H., $A$ microfluidic bioreactor with integrated transepithelial electrical resistance (TEER) measurement electrodes for evaluation of renal epithelial cells. Biotechnol Bioeng, 2010. 107(4): p. 707-16.

.39 Zhao, B., Zhang, Y., Li, X., Yang, X., and Huang, D., Comparison of indoor aerosol particle concentration and deposition in different ventilated rooms by numerical method. Building and Environment, 2004. 39(1): p. 1-8.

.40 Hinds, W.C., Aerosol technology: properties, behavior, and measurement of airborne particles. 20 :12John Wiley \& Sons.

.41 Zhang, H. and Ahmadi, G., Aerosol particle transport and deposition in vertical and horizontal turbulent duct flows. Journal of Fluid Mechanics, 2000. 406: p. 55-80.

.42 Herman, I.P., Physics of the human body. 2016: Springer. 
.43 Ferrell, N., Desai, R.R., Fleischman, A.J., Roy, S., Humes, H.D., and Fissell, W.H., $A$ microfluidic bioreactor with integrated transepithelial electrical resistance (TEER) measurement electrodes for evaluation of renal epithelial cells. Biotechnology and bioengineering, 2010. 107(4): p. 707-716.

.44 Horsfield, K., Morphometry of the small pulmonary arteries in man. Circulation research, 1978. 42(5): p. 593-597.

.45 Huh, D., Kim, H.J., Fraser, J.P., Shea, D.E., Khan, M., Bahinski, A., Hamilton, G.A., and Ingber, D.E., Microfabrication of human organs-on-chips. Nature protocols, 2013. 8(11): p. 2135.

.46 Sznitman, J., Respiratory microflows in the pulmonary acinus. Journal of biomechanics, 2013. 46(2): p. 284-298.

.47 Leslie, D.C., Domansky, K., Hamilton ,G.A., Bahinski, A., and Ingber, D.E., Aerosol drug delivery for lung on a chip, in 15th International Conference on Miniaturized Systems for Chemistry and Life Sciences. 2011: Washington, USA. p. 97-99. 